\title{
What Android mHealth Apps in Iranian App Store ‘Cafebazaar’ Have
} More Chance of Download

\author{
Hamid Naderi ${ }^{1,{ }^{*}}$ and Kobra Etminani ${ }^{1}$ \\ ${ }^{1}$ Department of Medical Informatics, Faculty of Medicine, Mashhad University of Medical Sciences, Mashhad, Iran \\ "Corresponding author: Department of Medical Informatics, Faculty of Medicine, Mashhad University of Medical Sciences, Mashhad, Iran. Tel: +98-5138002442, Email: \\ naderih932@mums.ac.ir
}

Received 2017 November 28; Revised 2018 November 04; Accepted 2018 November 05.

\begin{abstract}
Background: Mobile health applications are growing and some Iranian mHealth apps have been installed more than 200,000 times, which indicates their popularity is increasing rapidly in Iran.

Objectives: The objective of the current study was to detect predicators of mHealth apps download to forecast the app market. Methods: This study reviewed all medicine and health apps available in the most popular Iranian Android app store "Cafebazaar" and collected apps information up to November 20,2016.

Results: Of the 3331 studied apps, $24.4 \%$ were paid apps with prices ranging from 10,000 Rials to 300,000 Rials. The average number of apps published by a developer was eight. The effect of reviewed app variables was evaluated on the number of app downloads. There was heavy competition between mHealth app developers. There were several factors affecting the number of mHealth app downloads. mHealth apps with higher number of registered rating (P value $<0.001$ ), Internet availability (P value $<0.001)$, and using the camera (Pvalue $=0.03$ ) were more likely to download. On the other hand, application price $(\mathrm{P}$ value $<0.001)$ and number of previous apps published by a developer (P value $<0.001$ ) were inversely related to the number of app downloads.

Conclusions: Considering these predicators would help developers to become more successful in the mHealth market.
\end{abstract}

Keywords: mHealth, Mobile Apps, Market Forecasting, Download Predicators

\section{Background}

Mobile phones as a portable device are available at any time or place. They are an ideal medium and people's interest in the use of mobile apps in various fields has increased. One of the most popular areas is health, and apps in this field are modifying the lifestyle of people $(1,2)$. mHealth is defined by WHO as "an area of electronic health (eHealth) and it is the provision of health services and information via mobile technologies such as mobile phones and Personal Digital Assistants (PDAs)" (3). Every year, many mHealth apps are developed in the health field for different clinical conditions (4-8). Prediction indicates significant growth in mHealth apps development and introduction in health fields, as a top priority for application developers (9). There are different motivations for publishing mHealth apps. Helping people to improve health conditions, generating revenue, and data gathering are the most important goals of mHealth app developers. The mHealth app market is very young and attracts more newcomers every day. Although this market has a high potential, a limited percentage of developers achieve their business goals. Research2Guidance report shows competition in mHealth on the Production side (number of published apps) is growing faster than the requirement side (app downloads) (10). There is high failure risk for mHealth app developers with little or no experience in the field of health and lower income levels.

Some applications are rarely downloaded by users, while some other apps have been downloaded and installed more than several ten thousand times (11). To date, a few studies have characterized effective factors that influence the number of app downloads by users. Most of these surveys have only studied factors affecting the number of application downloads from the economical aspect (12-16). A few studies have considered some non-commercial influential factors. Mobile application developers submit several screenshots of the app with short description about features and functionality of the program at the time of publishing the application on the app store. These uploaded images and descriptions written about the app affect the user's decision when choosing apps for download $(12,17)$. Studies have shown that the size of mobile apps is inversely related to the number of downloads $(13,15)$. Large 
file size takes a long time to download and occupies additional space, thus increasing size of mobile apps reduces download count. Another survey pointed the time elapsed since published date of apps impacts the number of downloads, because app's age is an indicator for chance of user awareness. Releasing a new version of the app, in which the features of the program is updated, has a positive impact on the number of downloads (13). A recent study aimed at detecting predictors of urology app downloads (18). It only focused on urology-related scopes and reviewed 129 apps. The results of this study showed that applications with lower price, higher rating value, and greater number of reviews written by users were more likely to be downloaded. According to the results obtained from the analysis of most popular apps, developers can improve their design to develop and publish more user-friendly apps, which are closer to preferences of end users.

Cafebazaar is the largest Persian Android app store with more than 3500 apps in medical and health categories. Most Iranians download apps from this app store (19). The main aim of this study was to detect economic and non-economic predicators of mHealth apps download from the most popular Persian app store.

\section{Methods}

The researchers gathered information of all apps in two categories, health and medicine, in Cafebazaar as the most popular Persian Android app store up to November 20th, 2016. They wrote a program with PHP (which is a server-side scripting language) and MySQL database (version 5.6) to check the Cafebazaar app store website and gathered available information of published medical apps, automatically. The researchers checked all apps and excluded apps not related to health and medicine. In the next step, they excluded apps with missing value. All missing values appeared in rating value and rating count fields. Based on all available information, nine pre-determined variables were selected. All selected variables and their descriptions are listed in Table 1.

Because the exact number of downloads were not available in Cafebazaar app store, the researchers categorized them according to the classification system grade of installations used by this app store. Descriptive analysis and multivariate ordinal logistic regression were used to evaluate the effect of variables on the number of app downloads. Analysis was performed using Microsoft Excel 2010 and SPSS version 22 and P value values of $<0.05$ were considered statistically significant.

\begin{tabular}{|c|c|}
\hline Variables & Descriptions \\
\hline Number of app downloads & $\begin{array}{l}\text { Number of apps being downloaded } \\
\text { and installed }\end{array}$ \\
\hline 1 & $<100$ \\
\hline 2 & $100-200$ \\
\hline 3 & $200-500$ \\
\hline 4 & $500-1000$ \\
\hline 5 & $1,000-2,000$ \\
\hline 6 & $2,000-5,000$ \\
\hline 7 & $5,000-1,0000$ \\
\hline 8 & $10,000-20,000$ \\
\hline 9 & $20,000-50,000$ \\
\hline 10 & $500,00-100,000$ \\
\hline 11 & $100,000-200,000$ \\
\hline 12 & $200,000-500,000$ \\
\hline 13 & $>500,000$ \\
\hline Rating count & $\begin{array}{l}\text { Number of rates in the Bazar app } \\
\text { store }\end{array}$ \\
\hline Rating value & $\begin{array}{l}\text { User evaluation on a scale from } 1 \text { to } 5 \\
\text { stars }\end{array}$ \\
\hline App size & Application file size \\
\hline App price & Price of the app in Rials \\
\hline \multicolumn{2}{|l|}{ In-app purchase } \\
\hline 0 & No in-app purchase \\
\hline 1 & In-app purchase available \\
\hline Length of app name & Number of characters \\
\hline \multicolumn{2}{|l|}{ Using Internet } \\
\hline 0 & App doesn't connect to Internet \\
\hline 1 & App connect to Internet \\
\hline \multicolumn{2}{|l|}{ Using camera } \\
\hline 0 & Camera is not available \\
\hline 1 & Camera is available \\
\hline \multicolumn{2}{|l|}{ Using location or GPS } \\
\hline 0 & Location and GPS is not available \\
\hline 1 & Location and GPS is available \\
\hline $\begin{array}{l}\text { Number of released apps by a } \\
\text { company }\end{array}$ & $\begin{array}{l}\text { Number of other apps developed by } \\
\text { this company }\end{array}$ \\
\hline
\end{tabular}

\section{Results}

Information of 3602 apps (1836 apps from medicine category and 1766 apps from the health category) were gathered and 271 apps were excluded in two steps. Figure 1 shows the number of apps excluded at each step.

Of the 3331 remaining apps, $24.4 \%$ were paid apps with 


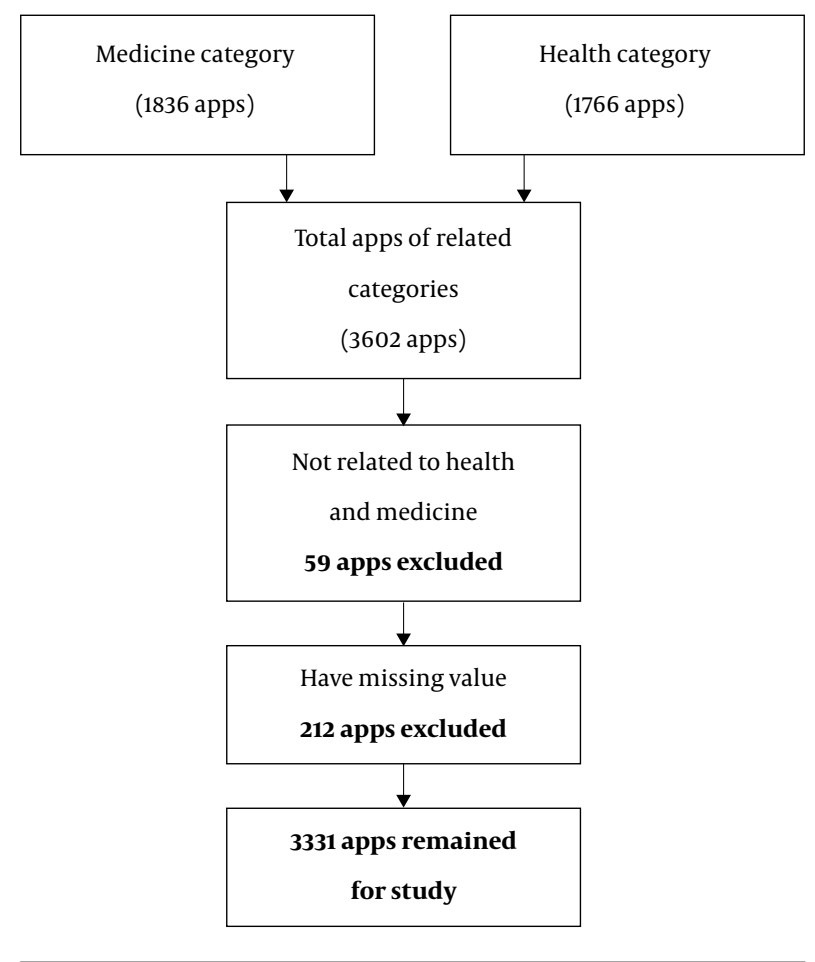

Figure 1. Exclusion inappropriate apps from study in several steps

prices ranging from 10,000 Rials to 300,000 Rials. Minimum and maximum number of apps developed by a person or company were one and 36, respectively (average of eight apps). The average of rating value for all of the apps was 4.26 and number of ratings ranged from one to 39,359 . Descriptive statistics for continuous variables with more details are listed in Table 2.

Frequencies for the categorical and binary variables are listed in Table 3. Overall, 32\% of apps had in-app purchase available. Furthermore, 2400 apps (72\%) could connect to the Internet. Location-based services like GPS was available in 121 apps and only $2 \%$ of apps used the camera.

The most number of app downloads were in four grades (grade 3 to grade 6), which is greater than 200 and less than 5000 (66\%). Only one app was downloaded more than 500,000 times. Ordinal logistic regression was used to identify predicators of mHealth app downloads. The results are shown in Table 4. Apps with a higher number of ratings were more likely to be installed ( $P$ value $<0.001$ ). Availability of Internet (Pvalue $<0.001$ ) and using the camera $(P$ value $=0.03)$ were also significantly associated with the app download. The number of apps developed by a company or person and app price were inversely related to the number of app downloads (P value $<0.001$ ).

\section{Discussion}

In the current study, different available factors were considered to detect predicators of mHealth apps download from one of the most popular Persian app stores. There is detailed information about published applications on most app store web sites. These information are available on app store websites to the public and you do not need to use a questionnaire to gather these factors. Therefore, analyzing these available factors as valuable resources can be used to forecast the app market.

The mHealth app market is a growing market and there is an increasing competition between mHealth app developers in this market. Some apps are downloaded over 10,000 times, while some others have been downloaded less than 100 times. This heavy competition on the supply side of mHealth to gain market share has led developers to pay greater attention to customers' needs and companies should have a more accurate forecast of the target market. The results of the current study characterized some factors influencing the number of mHealth app downloads. App stores are the most popular platform for the distribution of mHealth apps $(20,21)$. There is considerable information about published apps in app stores, which distinguishes them from traditional software deployment mechanisms. User feedback about the released apps is one of the most valuable resources for analyzing customer behavior. Many previous studies have pointed to customer feedback as a considerable information resource (22-24). The current results showed that apps with higher number of submitted comments were more likely to be installed. Previous studies mentioned that number of registered reviews on the Internet affects product sales and is considered as a predicator for the number of mobile app downloads $(13,14)$. Although users declare their feedback about an application in a variety of ways, such as submitting comments and rating, impact of each one is different. In the comments, application users can express their opinions with more details clearly. Therefore, it has a greater impact on users, who intend to download and install the app. Rating value of apps has a positive effect yet is not significant. This may be due to poor user attention towards app ratings. The results of the current study showed that price of apps is another predicator. Application price was inversely related to the number of app downloads, where inexpensive apps were more likely to be installed.

Users preferred apps, which could connect to the Internet and updated their content periodically $(11,25,26)$. Also, Internet and camera usage were indicators of social mHealth apps. Users can take pictures and share their health information and photos with family and friends on social networks. The results of the current study showed that Internet and camera usage are influential factors on 


\begin{tabular}{|c|c|c|c|}
\hline & Range & Median & IQR \\
\hline Rating count & $1-39359$ & 25 & 92 \\
\hline Rating value & $1-5$ & 4.40 & 0.7 \\
\hline App size (KB) & $71-94275$ & 2626 & 2970.5 \\
\hline \multicolumn{4}{|l|}{ App price (Rials) } \\
\hline All apps & $0-300,000$ & 0 & 0 \\
\hline Paid apps & $10,000-300,000$ & 20,000 & 10000 \\
\hline Number of released apps by a company & $1-36$ & 4 & 11 \\
\hline Length of app name (character) & $2-44$ & 15 & 10 \\
\hline
\end{tabular}

\begin{tabular}{lcl}
\hline Table 3. Frequencies of the Categorical and Binary Variables & \\
\hline Variables & Frequency & Percentage (\%) \\
\hline Number of app downloads & & \\
\hline $1:<100$ & 430 & 12.89 \\
\hline 2: $100-200$ & 330 & 9.90 \\
\hline 3: $200-500$ & 592 & 17.75 \\
\hline $4: 500-1000$ & 441 & 13.22 \\
\hline 5: $1,000-2,000$ & 554 & 16.61 \\
\hline 6: $2,000-5,000$ & 618 & 18.53 \\
\hline 7: $5,000-10,000$ & 191 & 5.73 \\
\hline 8: $10,000-20,000$ & 90 & 2.70 \\
\hline 9: $20,000-50,000$ & 64 & 1.92 \\
\hline $10: 50,000-100,000$ & 16 & 0.84 \\
\hline $11: 100,000-200,000$ & 5 & 0.15 \\
\hline $12: 200,000-500,000$ & 3 & 0.09 \\
\hline $13:>500,000$ & 1 & 0.03 \\
\hline
\end{tabular}

In-app purchase

0: No in-app purchase 2258

1: In-app purchase available

1077

32

Using Internet

0 : App doesn't connect to Internet

1: App connect to Internet

$935 \quad 28$

$2400 \quad 72$

Using camera

0 : Camera is not available

1: Camera is available

$3275 \quad 98$

60

Using location or GPS
0 : Location and GPS is not available

1: Location and GPS is available

\begin{tabular}{cc}
3214 & 96 \\
121 & 4 \\
\hline
\end{tabular}

application downloads. Apps that provide these features are popular and more likely to be installed. Results of the current analysis showed that the number of apps developed by a company or person was inversely related to the number of app downloads. There is a feature in most of app stores, which recommends other apps to be published by a developer. In most studied cases, previous released apps by a developer have a low quality and poor feedback. This study indicates that several variables, such as size of application, length of app name, and application purchase type have no significant impact on the number of downloads. Although some studies on generic mobile apps pointed these mentioned variables as predicators (12, $13,15)$, the current study confirmed the results of previous studies on mHealth, which was done on urology apps (18). Developers are struggling to achieve their goals yet the majority are not making money with mHealth apps (11). Based on predicted number of downloads, developer companies can estimate their future revenue. Also, the obtained predicators help developers define their marketing strategies based on target groups, such as pricing apps and scope of advertising.

\subsection{Limitation}

The current study had some limitations. In this study, only published mHealth apps in Cafebazaar, as the main Persian market for Android apps, were reviewed. The researchers did not review the content of user comments. Some users praise the app and announce their satisfaction, and a number of other users may have negative comments and have expressed the app's bugs. Other variables, such as age of application or version number of app have been reported as predicators for number of app downloads in some previous studies. These variable were not available in Cafebazaar as the proposed app store. Therefore their effects could not be considered in the current study.

\section{Footnotes}

Authors' Contribution: Study concept and design: Hamid Naderi, and Kobra Etminani. Acquisition of data: 


\begin{tabular}{|c|c|c|c|c|}
\hline & Coefficients & Standard Error & PValue & 95\% CI \\
\hline Rating count & 0.000551 & 0.000028 & $<0.001$ & 0.00049 to 0.00061 \\
\hline Rating value & 0.011975 & 0.050274 & 0.812 & -0.0866 to 0.11 \\
\hline App size (KB) & -0.000010 & 0.000006 & 0.059 & -0.00002 to 0.0000004 \\
\hline App price (Rials) & -0.000037 & 0.000002 & $<0.001$ & -0.000042 to -0.000032 \\
\hline In-app purchase & -0.103651 & 0.078617 & 0.187 & -0.2577 to 0.0504 \\
\hline Length of app name & 0.007451 & 0.004332 & 0.085 & -0.001 to 0.015 \\
\hline Using Internet & 0.564251 & 0.078488 & $<0.001$ & 0.4103 to 0.7181 \\
\hline Using camera & 0.556132 & 0.264556 & 0.036 & 0.0374 to 1.0748 \\
\hline Using location or GPS & 0.082138 & 0.191508 & 0.668 & -0.293 to 0.457 \\
\hline
\end{tabular}

Hamid Naderi. Analysis and interpretation of data: Hamid Naderi and Kobra Etminani. Drafting of the manuscript: Hamid Naderi. Critical revision of the manuscript for important intellectual content: Kobra Etminani. Statistical analysis: Hamid Naderi and Kobra Etminani.

Ethical Considerations: This manuscript was part of a PhD research. The researchers did not use any questionnaire or checklist to gather information. The information was gathered from Cafebazaar app store website that was available to the public.

\section{References}

1. Free C, Phillips G, Felix L, Galli L, Patel V, Edwards P. The effectiveness of M-health technologies for improving health and health services: A systematic review protocol. BMC Res Notes. 2010;3:250. doi: 10.1186/1756-0500-3-250. [PubMed: 20925916]. [PubMed Central: PMC2976743].

2. Batink T, Bakker J, Vaessen T, Kasanova Z, Collip D, van Os J, et al. Acceptance and commitment therapy in daily life training: A feasibility study of an mHealth intervention. JMIR Mhealth Uhealth. 2016;4(3). e103. doi: 10.2196/mhealth.5437. [PubMed: 27634747]. [PubMed Central: PMC5070582].

3. Torgan C. The mHealth summit: Local and global converge. Kinetics; 2009, [cited 2016 Mar 08]. Available from: http://caroltorgan.com/ mhealth-summit/.

4. Jibb LA, Stevens BJ, Nathan PC, Seto E, Cafazzo JA, Stinson JN. A smartphone-based pain management app for adolescents with cancer: Establishing system requirements and a pain care algorithm based on literature review, interviews, and consensus. JMIR Res Protoc. 2014;3(1). e15. doi: 10.2196/resprot.3041. [PubMed: 24646454]. [PubMed Central: PMC3978558].

5. Seto E, Leonard KJ, Cafazzo JA, Barnsley J, Masino C, Ross HJ. Mobile phone-based telemonitoring for heart failure management: A randomized controlled trial. J Med Internet Res. 2012;14(1). e31. doi: 10.2196/jmir.1909. [PubMed: 22356799]. [PubMed Central: PMC3374537].

6. Pham Q, Wiljer D, Cafazzo JA. Beyond the randomized controlled trial: A review of alternatives in mHealth clinical trial methods. JMIR Mhealth Uhealth. 2016;4(3). e107. doi: 10.2196/mhealth.5720. [PubMed: 27613084]. [PubMed Central: PMC5035379].
7. Goyal S, Morita P, Lewis GF, Yu C, Seto E, Cafazzo JA. The systematic design of a behavioural mobile health application for the selfmanagement of type 2 diabetes. Can J Diabetes. 2016;40(1):95-104. doi: 10.1016/j.jcjd.2015.06.007. [PubMed: 26455762].

8. Anderko L, Roffenbender JS, Goetzel RZ, Howard J, Millard F, Wildenhaus K, et al. Promoting prevention through the affordable care act: Workplace wellness. Prev Chronic Dis. 2012;9. E175. doi: 10.5888/pcd9.120092. [PubMed: 23237245]. [PubMed Central: PMC3523891].

9. Google Fit. The Google fit SDK. 2015, [cited 2016 Mar 08]. Available from: https://developers.google.com/fit/.

10. Reseach2Guidance. mHealth app developer economics. The current status and trends of the mHealth app market. 2016, [cited 2016 Oct]. Available from: http://research2guidance.com/r2g/r2g-mHealth-AppDeveloper-Economics-2016.pdf.

11. Naderi H, Etminani K. An evaluation of released mobile health apps in popular iranian app stores. Int J Med Engin Inform. Forthcoming 2018.

12. Decker R, Trusov M. Estimating aggregate consumer preferences from online product reviews. Int J Res Mark. 2010;27(4):293-307. doi: 10.1016/j.ijresmar.2010.09.001.

13. Ghose A, Han SP. Estimating demand for mobile applications in the new economy. Manag Sci. 2014;60(6):1470-88. doi: 10.1287/mnsc.2014.1945.

14. Davis A, Khazanchi D. An empirical study of online word of mouth as a predictor for multi-product category e-commerce sales. Electronic Mark. 2008;18(2):130-41. doi:10.1080/10196780802044776.

15. Telang R, Garg R. Estimating app demand from publicly available data. Pittsburgh, PA: Carnegie Mellon University; 2011, [cited 2016 Mar 08]. Available from: http://repository.cmu.edu/heinzworks/331/.

16. Sinkinson M. The determinants of supply and demand for mobile applications. [Working Paper \# 12-27]. Net Institute, The Wharton School University of Pennsylvania; 2012.

17. Ghose A, Ipeirotis PG, Li B. Designing ranking systems for hotels on travel search engines by mining user-generated and crowdsourced content. Market Sci. 2012;31(3):493-520. doi:10.1287/mksc.1110.0700.

18. Pereira-Azevedo N, Osorio L, Cavadas V, Fraga A, Carrasquinho E, de Oliveira EC, et al. Expert involvement predicts mHealth app downloads: Multivariate regression analysis of urology apps. JMIR mHealth uHealth. 2016;4(3). doi: 10.2196/mhealth.5738.

19. Saeedi MG, Kalhori SR, Nouri R, Yasini M. Persian mHealth apps: A cross sectional study based on use case classification. Stud Health Technol Inform. 2016;228:230-4. [PubMed: 27577377].

20. Minelli R, Lanza M. Software analytics for mobile applicationsInsights and lessons learned. 17th European Conference on Software Maintenance and Reengineering (CSMR). Genova (Italy). IEEE; 2013. p. 144-53. 
21. Al-Subaihin A, Finkelstein A, Harman M, Jia Y, Martin W, Sarro F, et al. App store mining and analysis. Proceedings of the 3rd International Workshop on Software Development Lifecycle for Mobile. August 31 - September 04, 2015; Bergamo, Italy. ACM; 2015. p. 1-2.

22. Hoon L, Vasa R, Schneider JG, Grundy J. An analysis of the mobile app review landscape: Trends and implications. [dissertation]. Faculty of Information and Communication Technologies, Swinburne University of Technology, Tech. Rep; 2013.

23. Pagano D, Maalej W. User feedback in the appstore: An empirical study. 21st IEEE International Requirements Engineering Conference (RE). July 15th-19th, 2013; Rio de Janeiro, Brazil. IEEE; 2013. p. 125-34.

24. Fu B, Lin J, Li L, Faloutsos C, Hong J, Sadeh N. Why people hate your app:
Making sense of user feedback in a mobile app store. Proceedings of the 19th ACM SIGKDD International Conference on Knowledge Discovery and Data Mining. August 11-14, 2013; Chicago, IL, USA. ACM;2013. p. 1276-84.

25. Fox S, Duggan M. Mobile health 2012. Pew Internet and American Life Project. Washington, DC: Pew Research Center; 2012, [cited 2016 Mar 15]. Available from: http://www.pewinternet.org/2012/11/08/ mobile-health-2012/.

26. Pew Research Center. U.S. smartphone use in 2015. Pew Internet and American Life Project. Washington, DC: Pew Research Center; 2015, [cited 2016 Mar 15]. Available from: http://www.pewinternet.org/ 2015/04/01/us-smartphone-use-in-2015/. 